\title{
The Geometry of Felix Escrig. Simplified Modelling Techniques for Modular Deployable Structures of Expandable Frames
}

\author{
Mauricio Soto-Rubio \\ University of Calgary, 2500 University Drive NW, Calgary, AB T2N 1N4, Canada
}

\begin{abstract}
This paper catalogues the morphology of modular deployable structures of expandable frames developed by the late Felix Escrig at the University of Seville, Spain. The research describes the geometric logic behind these structures, proposes simplified graphic methods for their design, and outlines their characteristics according to their level of geometric precision, structural stability and deployability. Finally, the paper establishes tools and guidelines for their future development.
\end{abstract}

Key words: Deployable, expandable, modular, collapsible, pantographic, scissor structures.

\section{Introduction}

Deployable structures of expandable frames, also known as scissor or pantographic structures, are defined by their capacity to transform from a closed or stowed configuration into an expanded one in a controlled and safe fashion [1]. These types of structures were first explored with rigor in architecture by the late Spanish architect Emilio Perez-Piñero, who developed among other projects a mobile deployable theatre based on an innovative system of three rigid members hinged concentrically together [2]. Pantographic structures were later popularized by architects such as Bodo Rasch and Chuck Hoberman, and have since been used in a wide variety of applications including bridges, roofs, facades and even toys. This technology was also explored for over 30 years by the late architect and dean of the architecture school at the University of Seville, Felix Escrig. His discoveries allowed a new generation of architects to develop adaptable projects that can respond to changes in climate, programmatic requirements or be

Corresponding author: Mauricio Soto-Rubio, professor, research fields: tensile fabric structures, deployable structures, and architectural pedagogy. deployed in remote locations to support first responders operating in areas affected by to natural disasters or humanitarian crisis.

The rules that govern the design of expandable frames deployable structures have already been extensively documented. In his book Modular, Ligero, Transformable, un Paseo por la Arquitectura Móvil [3] Escrig describes the morphology of these types of structures and presents the mathematic and geometric constraints required for these structures to be able to fold and unfold. Other architects and engineers such as Charis Gantes, Sergio Peregrino, Niels De Temmerman, Carlos Henrique Hernandez, Juan Perez Valcarcel, Masao Saito, and Luis Sanchez Cuenca have also developed innovative solutions based on deployable pantographic structures and documented their findings in numerous academic journals. Some of these authors also developed extensive classification systems for deployable structures in general [4]. One of the earliest attempts to classify deployable structures was Carlos Henrique Hernandez's thesis from the Massachusetts Institute of Technology in 1987 [5]. In this study, Hernandez described deployable structures as strut and surface structures, and subsequently divided them into 
scissor-hinged mechanism, sliding or umbrella mechanisms, hinged-collapsible-strut mechanisms, and inflatable, folded, and telescopic structures. In 1991, Gantes [6] classified deployable structures into pantographs, 2d panels, cable and membrane structures, pneumatic, tensegrity, and retractable structures with linear, radial or hybrid configurations. Later on, Pellegrino [7] described deployable systems as coiled rods, flexible shells, deployable membrane structures, articulated trusses, pantographs, retractable domes, etc. That same year, Hanaor and Levy [8] classified deployable structures into lattice and skeletal structures and continuous or stress-skin structures, and consequently into double-layer grids, single-layer grids, spine, folded plates and curved surfaces. The study also included deformable systems such as tensegrity and tensioned membrane structures. In 2004, Korkmaz [9] proposed a classification system based on whether building can change their geometry or their location. Further attempts to classify deployable structures include Schaeffer et al. [10], who differentiates between movement of rigid materials and deformable ones, Stevenson [11], who classifies structures according to physical transformation and their position in space and direction of transformation, Del Grosso and Basso [12], who classify them according to deformable and rigid links, and Adrover [13], who classifies them according to the technique used to generate them, such as origami or biometrics, and their structural components, such as rigid, deformable, flexible, or combined.

Despite the number of published classification systems for deployable structural systems in general, a comprehensive yet simplified catalogue that showcases the geometric properties of the different modular deployable structures of expandable frames developed by the late Escrig and his team is still missing. These integrated, self-contained, modules are particularly useful as they have the inherent capacity of being shipped to remote locations or areas affected by natural disasters and being deployed without the use of specialized machinery or personnel. However, despite the obvious potential, modular deployable structures of expandable frames have not yet been utilized in any meaningful way. This is at least in part due to the fact that the mathematical formulas and analytical descriptions often published in academic journals addressing the required geometrical relationships that make these structures possible are not always immediately accessible to all readers. This presents a barrier to their further development and mass implementation.

This paper classifies the main modular deployable structural systems of expandable frames developed by Escrig's team and presents simplified graphic modelling techniques that facilitate their understanding. The goal is to establish a solid yet simple base to encourage their future development.

\section{Basic Geometry of Expandable Frame Deployable Structures}

The scissor hinge or scissor-like-element (SLE) is one of the oldest and most commonly used elements in deployable architecture. At its most basic level, the makeup of a scissor unit consists of a hinge connecting two rigid members [14]. Several SLEs can then be connected to each other to generate a flat expandable frame (Fig. 1). Similarly, the elements can also be connected on different intersecting planes to create a variety of structural configurations that can expand and contract in two or three dimensions (Fig. 2). The resulting units can then be added together to generate a deployable bundle (Fig. 3) [15]. These variations were first developed and patented by Escrig in 1984 [16] and became the basis of many of his designs.

The basic geometric relationship that allows expandable frames made with scissor structures to be fully deployable is known as the deployability constraint [1]. According to the terms defined on Fig. 1, this relationship states that:

$$
A+B=C+D
$$




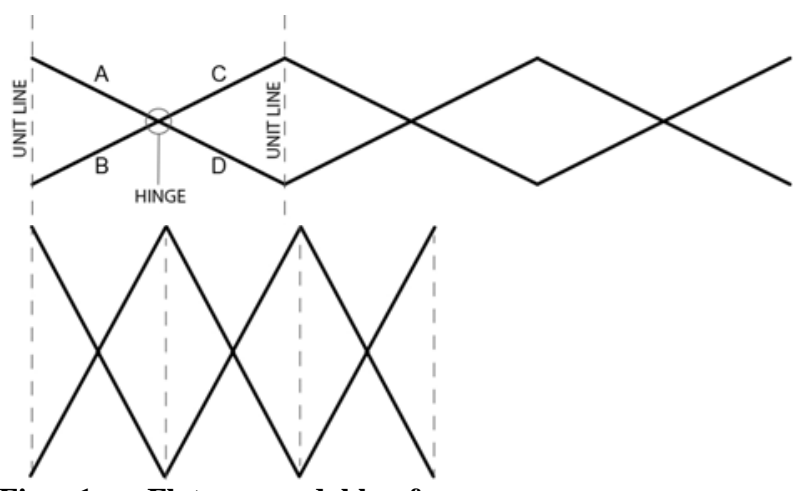

Fig. 1 Flat expandable frames are one or more scissor-like-elements connected together. They are designed to expand and contract in two directions.
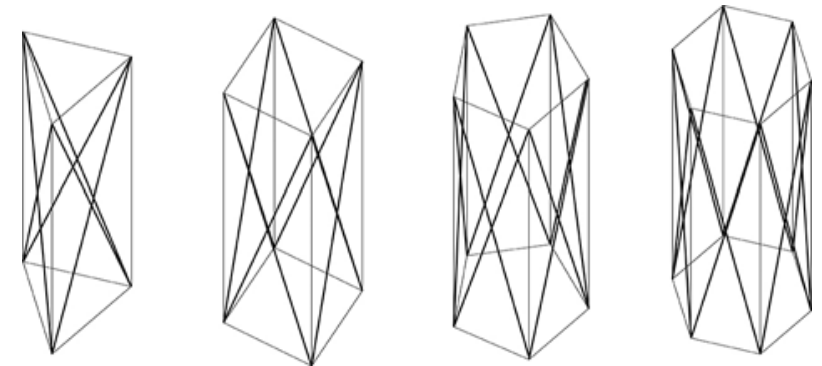

Fig. 2 Scissor units connected to each other forming polygons of different number of sides. These structures expand and contract in three directions.

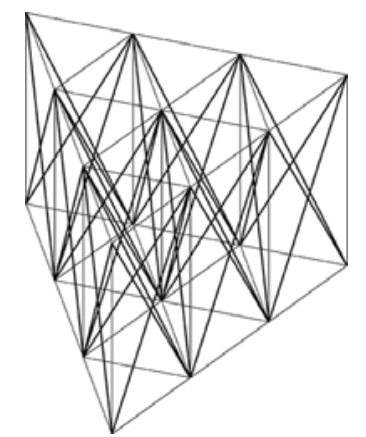

Fig. 3 Multiple polygons connected together to generate a fully expandable space frame.

Some of the advantages of flat expandable frames include having rigid members of similar lengths with hinges at their center, which significantly simplifies their fabrication and potential future replacement. However, these structures do not significantly increase in height when deployed, which limits their potential to define any programmable space. To provide a greater volume, scissor elements must have an off-centered connection (Fig. 4), which produces a structure that expands along an arch and grows both horizontally and vertically [17].

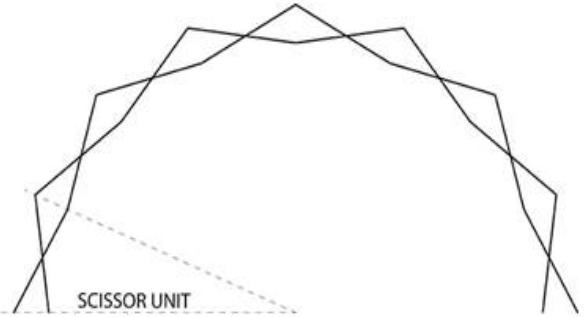

Fig. 4 Off-centered hinge scissor unit deploy along an arch, generating a frame grown both horizontally and vertically.

\section{Geometric Alternatives}

\subsection{Polar and Translational Frames}

The difference between Polar and Translational Unit frames is based on how the unit lines of each scissor unit relate to the structure as a whole. In polar scissor structures each unit line remains aligned to a central point that defines the arc of the structure. In this case, all scissor units are exactly the same, and are repeated around the central point (Fig. 5). The unit lines on translational scissor structures are parallel and equidistance to one another and do not relate to a central point (Fig. 6). The scissor units in this case are all different according to their position on the structure.

The creation of parallel unit lines in translational scissors allows greater design freedom to create asymmetric scissor structures. A deployable translational scissor can follow any curve (Fig. 8).

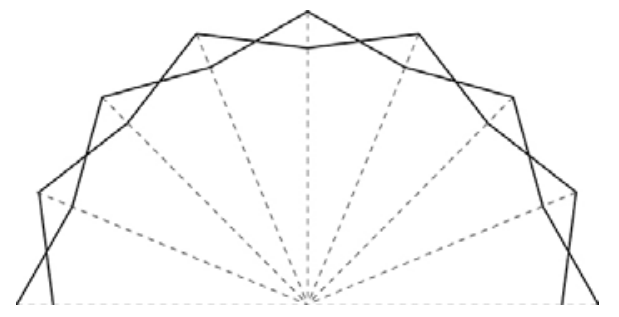

Fig. 5 Polar scissor structure.

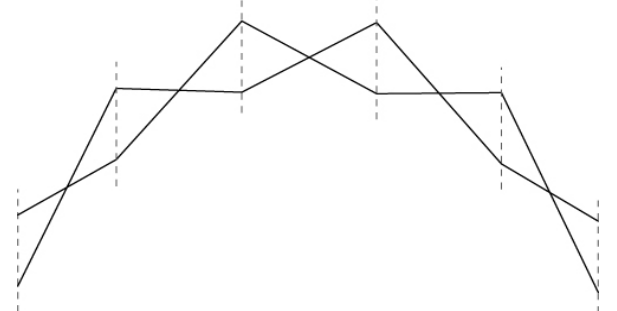

Fig. 6 Translational scissor structure. 

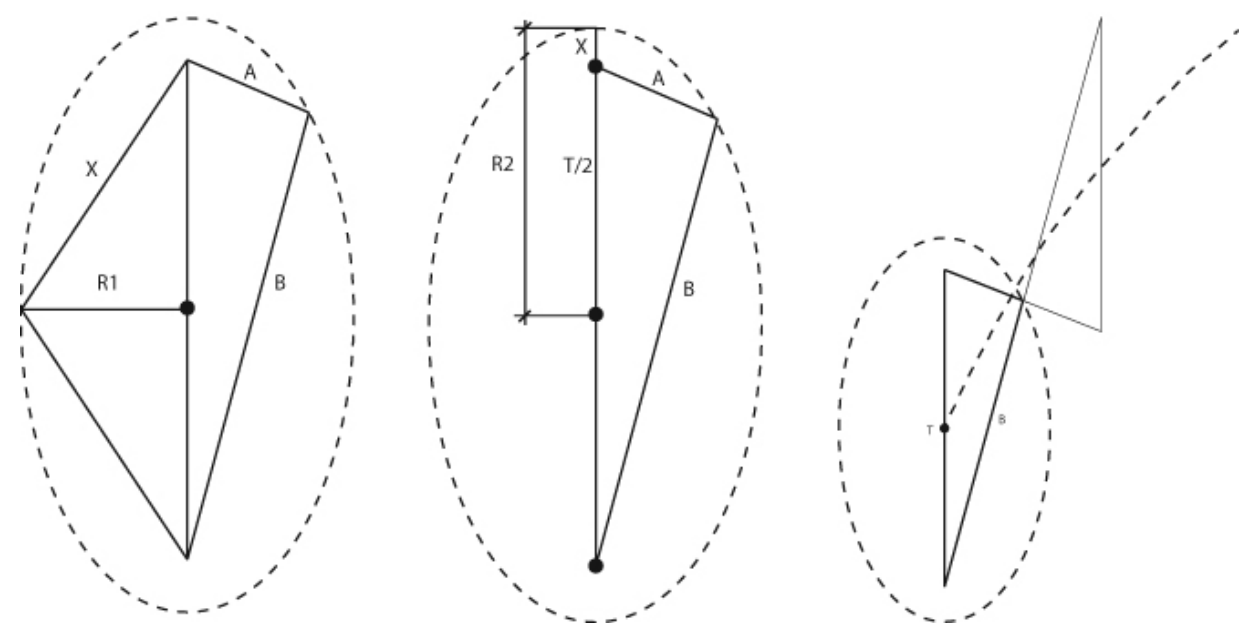

Fig. 7 Non-symmetric deployable translational frame ellipse calculation.

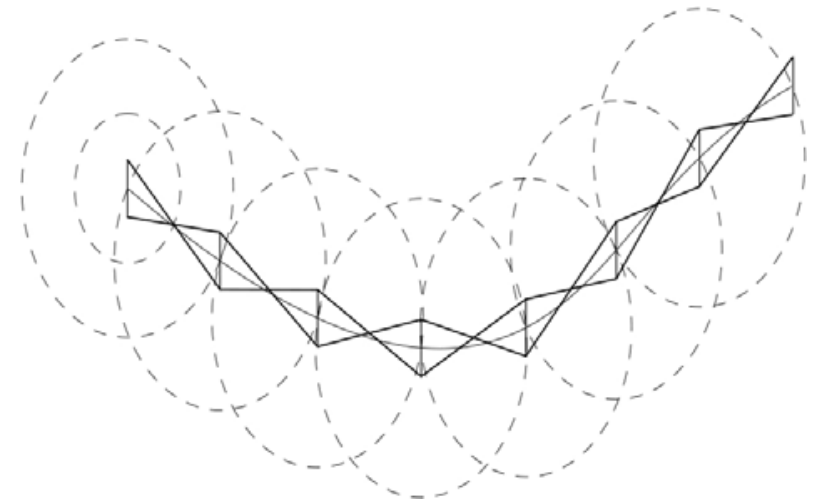

Fig. 8 Non-symmetric deployable translational frame. Ellipses allow the system to follow any curve or arch.

A translation SLE design based upon a variable curve requires the construction of an ellipsis based on the unit line depth T. Using the mathematical Eq. (2) depicted in Fig. 7 each of the dimensions of the ellipses is determined. This ellipse is scaled by a factor of 2 around the center point of this unit line. The point at which the smaller ellipse intersects the curve delineates the location of the first hinge. The intersection point of the larger ellipse locates the center point of the adjacent unit line. Using the same ellipse sizes this process is repeated at the adjacent unit line to determine the next component. This process can be repeated until the end of the curve is reached, or until the translated ellipses no longer intersect the curve [1].

$$
R_{1}=\frac{A+B-T}{2}-\frac{T}{2}, R_{2}=\frac{\sqrt{A+B^{2}}}{2}-\frac{T^{2}}{2}
$$

\section{Typologies}

As previously mentioned, deployable structures of expandable frames can be used in a wide variety of applications including bridges, roofs, facades, as well as modular deployable units. This last typology capitalizes on the inherent lightweightness and mobility of the system to serve a wide variety of programmatic activities including temporary deposits, outdoor events or exhibitions, as well as emergency shelters that can be rapidly deployed to support victims and first responders operating in remote areas affected by natural disasters [18]. In order to protect the space against weather conditions and enable the previously mentioned programmatic activities, these mobile units are typically used in combination with tensile membrane structures [19] or rigid panels [20].

Modular deployable structures of expandable frames can be classified under three main typologies: Vaults, Domes, and Pendentives. Each of these typologies can be further categorized by their geometrical configuration in either polar or translational. In addition, some of these categories can be made with either a rectangular grid (2-way), or a triangular grid (3-way).

\subsection{Vault}

A vault of pantographic structural elements is a linear repetition of identical scissor arches parallel to 
one another. There can be as few as two arcs up to as many arcs as desired in length. These parallel arcs are then connected by linear scissor elements. The deployability constraint previously explained must be applied to each scissor element in the arches as well as the connecting elements between them.

\subsubsection{Vault-Polar-2 Way (Fig. 9)}

The distance between arches is determined by the need to comply with the deployability constraint. The following formula describes the geometrical relationship between the length of the scissor components $\mathrm{A}$ and $\mathrm{B}$, the length of the unit line $\mathrm{T}$ and the distance between the arches $\mathrm{D}$.

$$
D=\left[\sqrt{\left(\frac{A+B}{2}\right)^{2}-\left(\frac{T}{2}\right)^{2}}\right] \times 2
$$

The depth of the scissor elements $\mathrm{T}$ and the number of segments can easily be increased or decreased. Both changes will affect the distance between arches D. After this is determined, any number of additional arches can be added to the structure to increase the structures length providing variable volume. The single curvature of a 2-way vault structure and the fact that all intersecting scissor elements generate square frames make this tape of structure inherently unable to resist lateral loads without additional bracing elements. Although the fabric typically used with these modules can sometimes contribute to the lateral stability of the module, bracing at least $25 \%$ of the existing bays is recommended. In addition, it is highly beneficial to add structural elements along the polar unit lines of each arch after deployment as this will secure the structure in the open position and provide additional stability.

Preliminary structural analysis of this configuration indicates that maximum stresses are typically concentrated on one of the two elements of each scissor-like-structure according to the direction of the wind [21].

\subsubsection{Vault-Translational-2 Way (Fig. 11)}

This module is defined by a series of translational arches joined together by identical parallel Scissor-Like-Elements (SLEs). This structure ability to comply with the deployability is determined through the use of Eq. (3) defined in Fig. 10. The Translational 2 Way Vault is less easily manipulated due to the interdependence of unit line length $T$ and space between unit lines required in the design of a translational pantographic scissor arch. However, the ability to follow arches of any form, including circular or parabolic, provides the opportunity to create modular structures of different heights and spans.

As seen in plan-view, the rectangular bays of this module make it susceptible to lateral forces which suggest the need for additional diagonal bracing elements to be installed after deployement. Similar to previous configurations, the addition of structural elements along unit lines on each arch will fix their
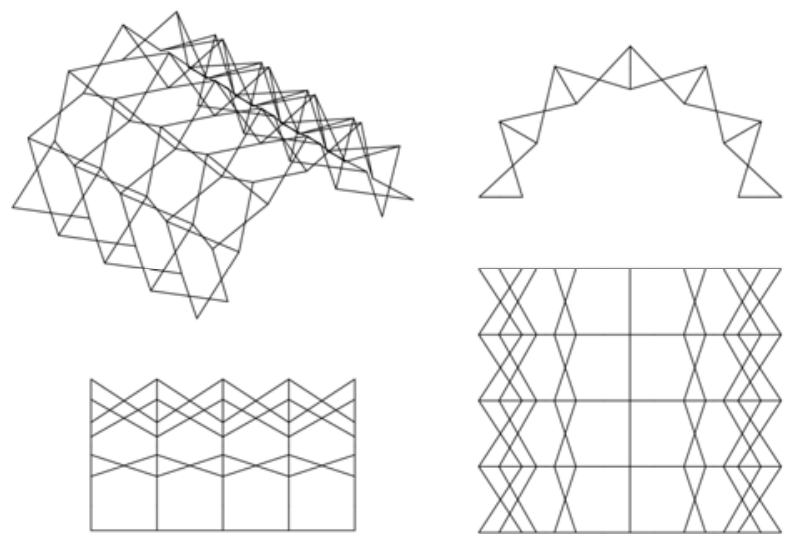

Fig. 9 Vault polar 2 way modular deployable structure.

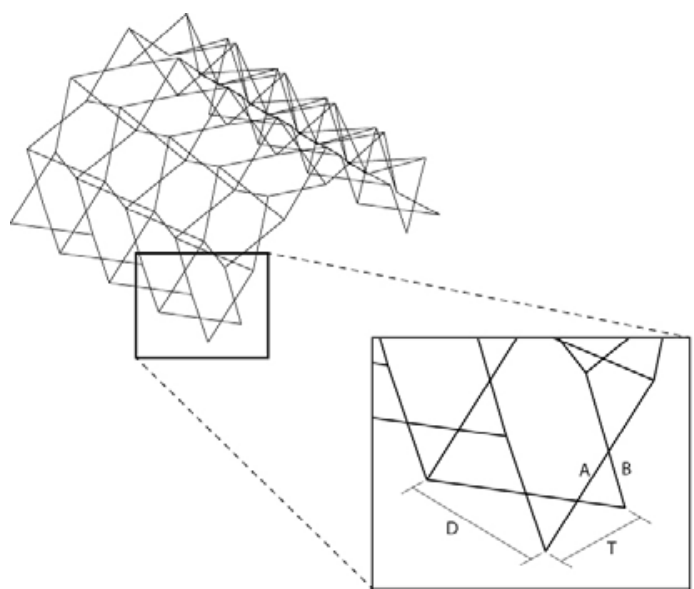

Fig. 10 Relationship between arch geometry and connection spacing. 

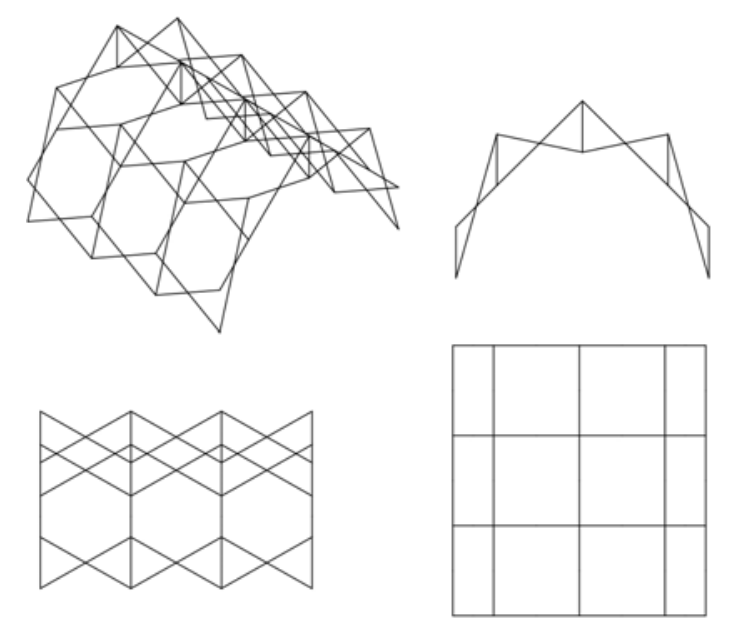

Fig. 11 Vault-translational-2 way.
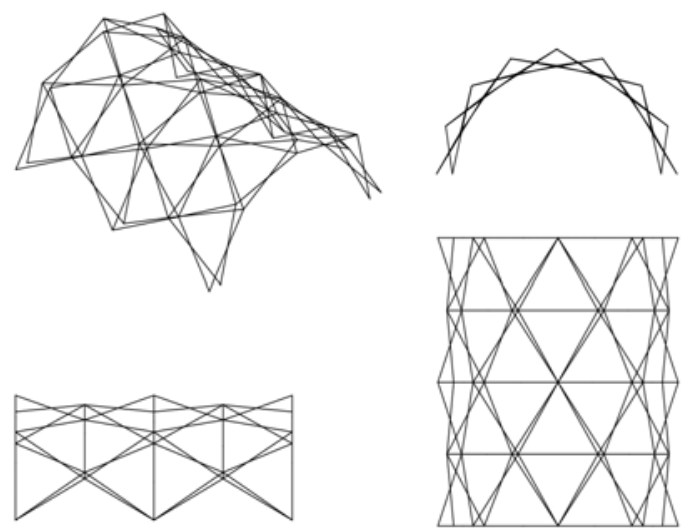

Fig. 12 Vault-polar-3 way-variant 1.
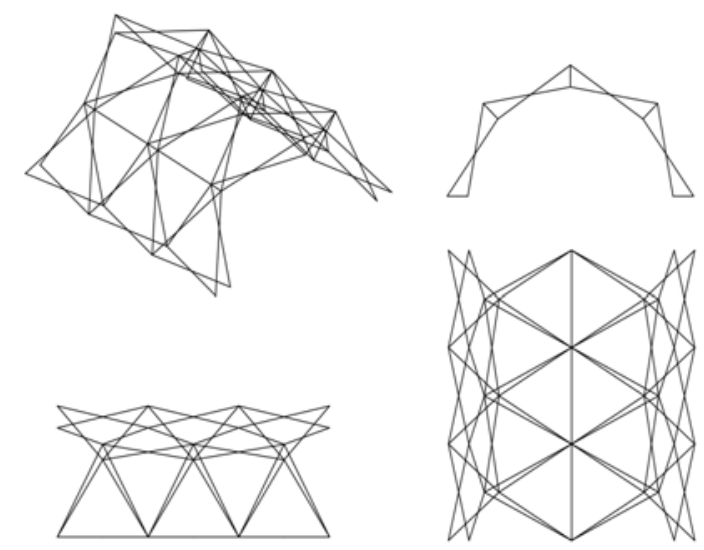

Fig. 13 Vault-polar-3 way-variant 2.

geometry and add additional stability to the structure. Preliminary structural analysis also locates the concentration of maximum stresses on one side of the structure depending on the direction of the wind [11]. In addition, these studies also suggest higher stresses in translational designs in comparison with polar arraignments [11].

\subsubsection{Vault-Polar-3 Way-Variant 1 (Fig. 12)}

This design is comprised of a series of polar arches parallel to one another. The second and fourth arches in this design are rotated half a SLE. Additionally, planar Scissor-Like-Elements run diagonally across the vault structure linking all arches together. The distance between arches is determined by making sure that the diagonal scissor elements comply with the deployability constraint of the system. Within a diagonal element a geometrical problem arises in which the 2 crossing members are pulled onto different planes, preventing a connection point at the fulcrum of the scissor [22]. This inevitable inaccuracy can be addressed when the minimal cross-dimensional properties of the structural elements are considered. In "Estructuras Espaciales Desplegables Curvas" [23], Escrig also proposes solving this issue by using curved bars, which have to be forced to a straight position when the structure is collapsed. The strain energy stored in the bars could potentially be used during the deployment process.

\subsubsection{Vault-Polar-3 Way-Variant 2 (Fig. 13)}

This structure is a variation of the Polar 3 Way vault in which the arches are replaced by sets of scissor elements that run along the entire vault. 3-way structures are inherently heavier than 2-way systems, however, the lateral stability of 3-way vault structures depends on the inherent stability of the triangular configuration of their bays. Therefore, these options require no additional bracing elements. However, additional elements along unit lines should be installed after deployment to fix the geometry of the module in its open configuration.

\subsection{Domes}

A dome scissor structure is the combination of two or more intersecting sets of scissor arches. The arches can be circular or parabolic and their scissor elements are normally symmetrical. A large array of options has been documented; however, the designs predominately 
follow polar configuration [24] and are circular in plan [25].

The options described in this study are all modular and able to be transported as a bundle in their closed configuration. Other dome options not included here collapse along the circumference of their base and deploy towards the center of the dome. These options are arguably less useful for mobile applications as they are much more difficult to transport and typically leave the center of the dome uncovered.

\subsubsection{Dome-Polar-2 Way-Great Circles (Fig. 14)}

This modular variation is built by running a polar arch along each of the great circles in the $\mathrm{X}, \mathrm{Y}$, und $\mathrm{Z}$, axis of the sphere. The arch at the base can then be omitted according to the specific supporting conditions of the proposed design. In this case however, extra diagonal elements are required after deployment to stabilize the dome, which could otherwise collapse laterally or by torsion. Since the geometric organization of arches is polar, the depth of the unit lines $\mathrm{T}$ can be manipulated without effect on the other variables.

In this option, additional scissor-like elements connect between the main arches in a triangular pattern. In order to preserve the deployability constraint, these secondary SLEs tend to be highly asymmetrical.

This design was made famous by the architect Hoberman [26], who patented it in 1991 and used it as the basis of many of his deployable toys.

4.2.2 Dome-Polar-2 Way-Meridians and Parallels (Fig. 15)

This modular design is characterized by arches that follow the meridians and parallels of a dome. Escrig [3] describes this configuration as one of the most promising geometries for the design of modular deployable structures of expandable frames. Dividing a sphere in meridians and parallels produces a trapezoidal grid of sufficient lateral stability. However, this also generates scissor structures and structural elements of many different sizes, which complicates its design and fabrication.
In his paper "Las Cubiertas Desplegables de Malla Cuadrangular” [27] Escrig mathematically describes the angular relationship between meridians and parallels that allows the deployability constraint to be possible in all scissor like elements of the system. However, this relationship can be graphically described by the circle-packing graphic methodology [28] which greatly simplifies the design process. The process can be applied to many different cases. For parallels and meridians, the methodology can be described with the following steps (Figs. 16-18).
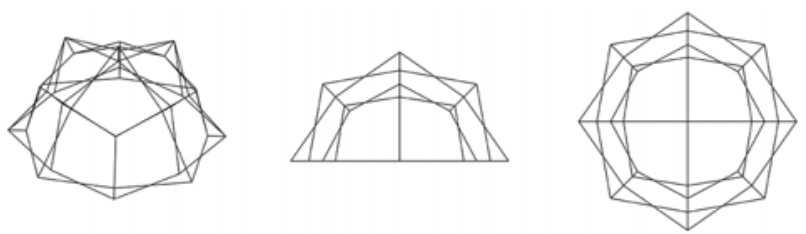

Fig. 14 Vault-polar-2 way-great circles.
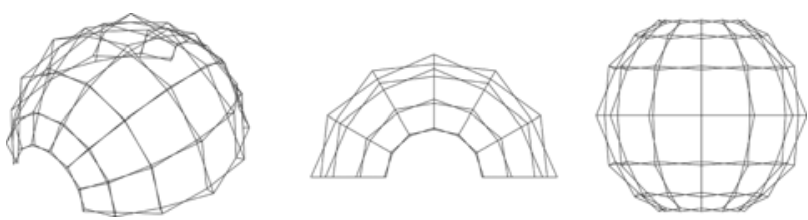

Fig. 15 Vault-polar-2 way-meridians and parallels.

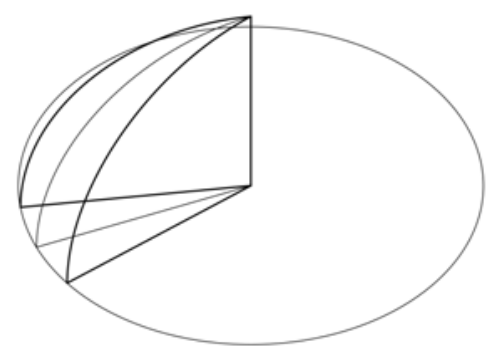

Fig. 16 Step 1: divide the base of the dome into an equal number of parts. Select one segment to design the SLE.

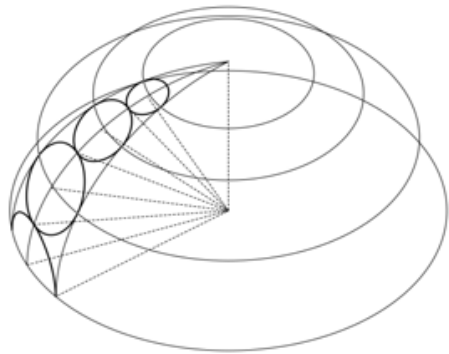

Fig 17 Draw meridians from the base of the dome to its pole. Draw circles that are tangent to the meridians and to each other. 


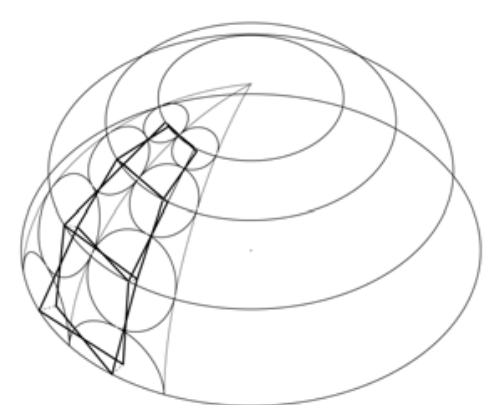

Fig 18 Draw lines from the centre of the circle and the intersections between them to the centre of the dome. These correspond to the unit lines of the SLE. Starting at the base of the dome, draw the first scissor element. Each unit line corresponds with the lines drawn to the circle centres. The pin connections will align with the lines drawn to the tangent connections between circles.

\subsubsection{Dome-Polar-2 Way-Lamellas (Fig. 21)}

The Polar 2-way Lamella Dome can be designed following the previous circle-packing design strategy with a slight change of the layout of the tangent circles. As a result of the incrementally smaller size of each tier of SLE, a large variation in component size creates a higher level of complexity in the fabrication of lamella style domes. The design of a lamella dome can be described in Figs. 19-21.

\subsubsection{Dome-Polar-2 Way-Geodesic (Fig. 23)}

All geodesic domes are derived from subdividing the faces of an icosahedron, which is a basic shape made with 20 equilateral triangular faces that approximate a sphere. Any subdivision that is an even number-such as frequency 2, 4, 6, etc. provides for a flat base for a dome. After the face is subdivided each of the points not located at the original triangular face's corner is moved on a vector away from the center of the icosahedron until it hits the surface of the enclosing sphere.

The governing geometry of geodesics dome provides all triangles with the same dimensions, which results in a pantographic structure comprised of identical components. This simplifies component fabrication or replacement and facilitates the compliance with the deployability constraint independent of unit-line depth.

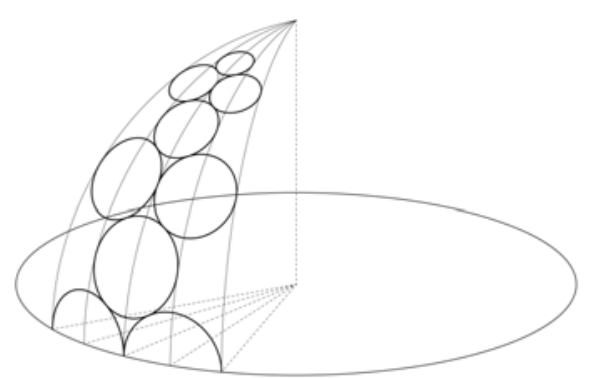

Fig. 19 Divide a circle into equal parts as in the previous method. Additionally, each part must be subdivided one more time to find a meridian that meets the centre point of each initial segment.

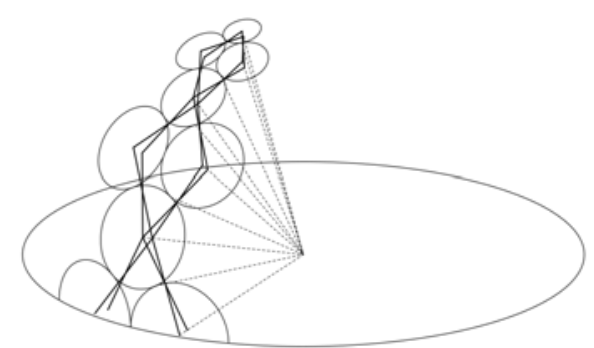

Fig. 20 Draw circles in each initial section that are tangent to the boundary meridians. The second tier of circles is drawn tangent to the first circles and the centre meridians of each segment. The third tier returns to the initial logic, drawing a circle tangent to the second-tier circle and the boundary meridians. This alternating pattern continues until the desired number of SLE guide circles is achieved.

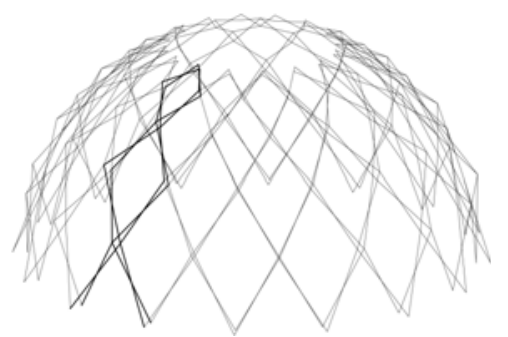

Fig. 21 Draw lines from the centre of the circles and the intersections between them to the centre of the dome. The relationship of SLE to these lines remains the same, in which the unit lines will fall along the centre of the circles and the hinge points of each SLE fall upon the lines drawn to the connection points between circles. Choosing the length of the unit lines at the base of the dome will determine the length of all subsequent unit lines.
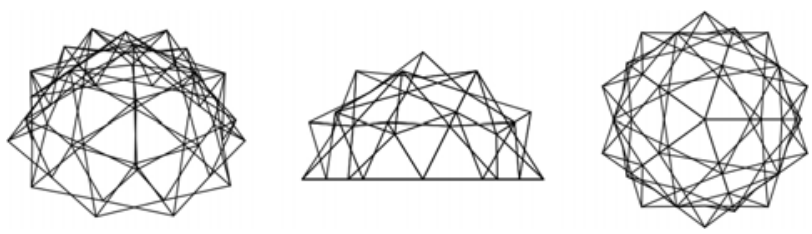

Fig. 22 Dome-polar-2 way-geodesic. 

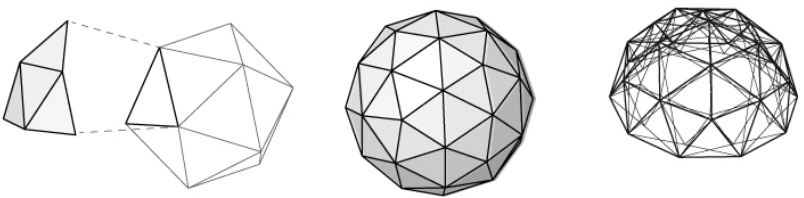

Fig. 23 Governing geometrical logic of geodesic deployable structure. An icosahedron with 20 equilateral triangles is subdivided. Lines from the center of the sphere to the corners of the triangles form the unit lines for the scissor-like-elements.
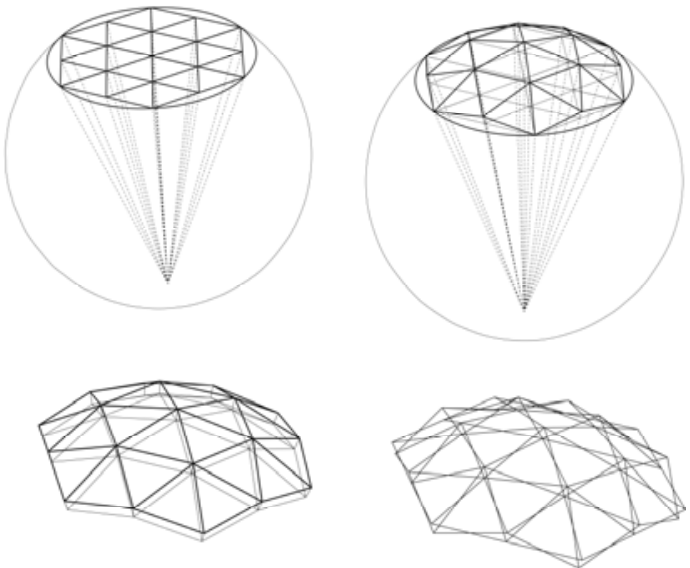

Fig. 24 Design process for spherical 3-way deployable domes. A geodesic design will have its focus point at the center of the sphere.

In terms of structural performance, preliminary comparative analysis has identified this design as extremely efficient in terms of loads and stress distribution [11]. In his studies, Escrig [3] presents an alternative methodology for the design of different 3-way polar domes. In this case, the unit lines are projected from an arbitrary point in space, though a triangular grid inside the sphere, and onto its surface. These points are then joined to create a matrix that defines the scissor-like-elements (Fig. 24). This innovative strategy produces structures with scissor-like elements of different sizes, and geometries that are stable only when fully collapsed or fully opened, but that produced drastic deformations on structural members during all intermediate stages of deployment. In his book Modular, Ligero, Transformable. Un Paseo por la Arquitectura Ligera móvil [3], Escrig speculates about the potential use of the strain energy stored in the bent bars to facilitate the deployment process and to avoid the structure to open or close inadvertently. This design process was implemented to develop an entry for a design competition for a 60-m span deployable roof for a swimming pool complex in Mairena del Aljarafe in Seville and a 120-m span deployable cover for a sky-jump structure in Austria [29]. In both these cases, the focal point for all unit lanes was carefully selected to minimize discrepancies in the sizes of scissor-like elements.

Depending on the grid used and the polygon it forms, this design process can be used to create a myriad of alternatives. The strategy can also be used to generate 2-way deployable domes [24]. One example of this option is the roof for the swimming pool of the San Pablo sports center in Seville designed by Escrig in 1996. In this case, the unit lines project from the center of the sphere and produce a deployable dome with scissor-like elements of similar sizes [30]. The project covers an Olympic size swimming pool of $25 \mathrm{~m} \times 50 \mathrm{~m}$ with two domes of 30 $\mathrm{m} \times 30 \mathrm{~m}$ using a quadrilateral grid of $6 \mathrm{~m} \times 6 \mathrm{~m}$ and aluminum structural tubes of dia. $120.5 \mathrm{~mm}$ [31].

\subsection{Pendentive}

Pendentive structures are characterized by arches that form the perimeter of a square base and similar subsequent intersecting arches are placed on them. The arches can be circular or parabolic and the deployable frames can be pendentive or polar. The square configuration of these structures suggests 2-way grids [32].

\subsubsection{Pendentive-Polar-2 Way (Fig. 25)}

In a modular Polar Pendentive 2-way structure each arch is comprised of identical scissor elements, which simplifies the design and manufacturing process and facilitates the compliance with the deployability constraint in the system. Despite the double curvature of this design, the square bays generated by the intersecting arches produce insufficient lateral stability, which suggest the need to extra diagonal bracing 

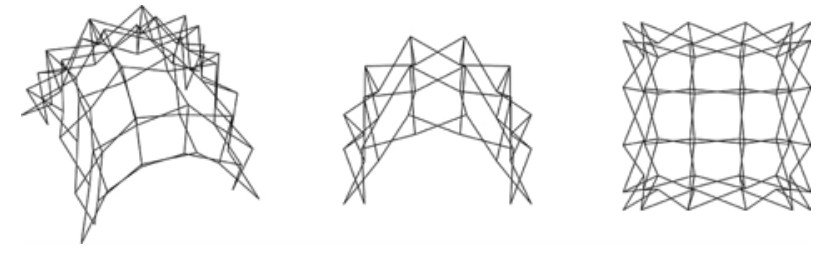

Fig. 25 Pendentive-polar-2 way.
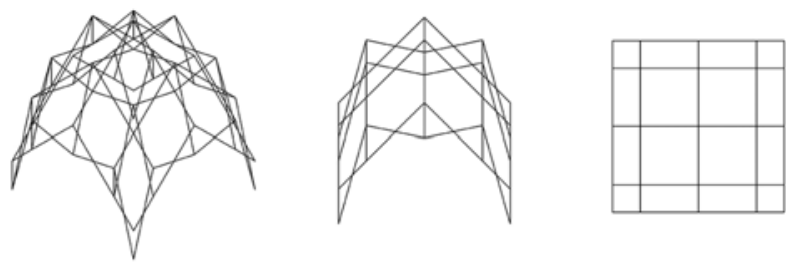

Fig. 26 Pendentive-translational-2 way.

elements such as struts or cables [33]. Preliminary comparative structural analysis of modular deployable structures indicates that maximum stresses in pendentive structures are typically located at the base of the modules. Similarly to previously discussed 2-way vault configurations, polar arrangements seem more efficient than translational options [11].

\subsubsection{Pendentive-Translational-2 Way (Fig. 26)}

In a modular Translational Pendentive-2 Way structure, all arches in the system are identical. However, the translational nature of the arches produces irregular scissor-like elements which increases the complexity of the design and fabrication process. As seen on plan, the uniform square organization of the SLEs is very unstable to lateral forces and requires diagonal bracing elements to be installed after deployment.

\section{Structural Considerations}

In order to develop a deep and robust understanding of the structural behavior of modular deployable structures of expandable frames, it is important to discuss issues such as envelop systems, materials, joints, and erection systems.

\subsection{Envelop Systems}

In order to house any programmatic activity, modular deployable structures are often integrated with a tensile fabric cover. This membrane provides the necessary weather protection, but also transfers additional loads (i.e. wind, and snow) to the expandable frames. Covers are typically made of Teflon (PTFE) or polyester coated PVC or other materials that do not lose tensile strength after repeated folding and unfolding. In most cases the envelope systems are transported separately and installed on the frames after these are deployed. However, projects that do not change location have been designed to be expanded while the fabric is connected to the frames. Since the fabric must be able to adequately transmit forces, a certain level of double curvature is necessary. This is typically achieved by confectioning the cover with patterns which are sawn or welded together.

The fabric can also provide additional lateral stability to the modules. As previously described, modules with rectangular 2-way frames are inherently unstable and commonly require diagonal stiffeners after deployed. The fabric however has the inherent capacity to brace 2-way frames and horizontally stabilize the modules. This can be particularly useful in structures of reduced dimensions.

\subsection{Joints}

The joints of a deployable modular structure should transmit forces evenly between members and provide sufficient freedom of movement to allow the structure to open and close, while at the same time minimizing friction between moving parts and reducing material fatigue [5].

\subsection{Materials}

Since transportability and easy deployment is one of the main considerations in the design of this type of modular structures, lightweight materials such as aluminum are commonly used. However, the selected materials must be able to withstand the initial loads acting on the structure, the additional stresses caused during deployment, as well as the transferring of forces that can occurred between members not bonded 
together by the pressure exerted of one body onto another. This is particularly important at the joints, where the flow of compressive or tensile stresses increases which can cause transversal tension to develop. As a result, the affected element may crack and split longitudinally if appropriate measures are not taken.

\subsection{Erection}

The main advantage of modular deployable units is the possibility of transporting and deploying them without the use of specialized machinery or personnel. During the deployment of the Estran 1 module, Hernandez and his team demonstrated that lifting the structure by its center was enough to release the friction at all joints and deploy the structure effortlessly. If the module is located on a relatively flat and smooth surface, casters or rollers can also be used to open the legs of the module. Other opening and closing mechanisms include hydraulic systems, motor and manually driven screws, etc.

\subsection{Comparative Strength of Geometries}

Although it has been proven challenging to compare the structural performance of the individual structural geometries developed by Escrig, initial studies published by Soto-Rubio and Jew [21] indicate that under exactly the same loading conditions, span, material and cross sectional properties, vault polar configurations can be up to two times more efficient than their translational counterparts. Similarly, pendentive polar structures can be four times more efficient than their translational versions.

\section{Conclusion}

Modular deployable structures of expandable frames, commonly known as pantographic or scissor frames, are structures that can expand from a closed configuration into an opened one in a safe and controlled way. Combined with tensile fabric structures, these deployable systems can effectively activate spaces that can be used as emergency medical units in remote areas affected by natural disasters, stages in music festivals, temporary deposits, etc. The late Spanish architect Felix Escrig and his team at the University of Seville worked for over 30 years in the design of these structures. His various academic journals and books document the geometrical relationships that make modular deployable structures possible and present innovative design solutions that showcase their potential.

Despite the important advances in the area of deployable structures, this technology has not been extensively in emergency architecture. This is, at least in part, due to the complexity associated with these structures. In addition, the geometrical relationships that make these structures possible are commonly described in mathematical terms, which are not always accessible to the common reader. Architects and engineers interested in this area must first familiarize themselves with the basic concepts and rules that guide these structures and explore various alternatives before proposing a solution for a specific project. This paper intends to facilitate this process by comparing and contrasting some of the most common geometries used for the design of modular deployable structures and propose innovative graphic methods that simplify their design. The study does not pretend to be all-inclusive or complete, but it does present an important range of geometric possibilities for the design of this type of structures. The various geometries presented can be evaluated according to their individual strengths and weaknesses, including access, lateral stability and modularity of structural elements. The goal of the study is to establish guidelines for the design and future development of these structures.

\section{References}

[1] De Temmerman, N. 2007. "Design and Analysis of Deployable Bar Structures for Mobile Architectural Applications.” Doctor thesis, Vrije Universiteit Brussel.

[2] Puertas del Rio, L. 1989. "Estructuras Espaciales 
Desmontables y Desplegables, Estudio de la Obra del Arquitecto Emilio Perez Piñero.” Excuela Tecnica Superior de Arquitectura de Madrid, Madrid.

[3] Escrig, F. 2012. "Modular, Ligero, Transformable." In un paseo por la arquitectura ligera móvil. Spain: Universidad de Sevilla.

[4] Fenci, G. E., and Currie, N. G. 2017. "Deployable Structures Classification: A Review.” Int. J. Space Struct. 32 (2): 112-30, doi: 10.1177/0266351117711290.

[5] Hernandez, C. 1987. "Deployable Structures.” Master thesis, Massachusetts Institute of Technology.

[6] Gantes, C. 2001. Deployable Structures: Analysis and Design. Southampton: WIT Press.

[7] Pellegrino, S. 2001. "Deployable Structures in Engineering." International Centre for Mechanical Sciences 412: 1-35.

[8] Hanaor, A., and Levy, R. 2001. "Evaluation of Deployable Structures for Space Enclousures.” Int. J. Space Struct. (16): 211-29.

[9] Korkmaz, K. 2004. An Analytical Study of the Design Potentials in Kinetic Architecture. Izmir: Izmir Institute of Technology.

[10] Schaeffer, O., Vogt, M., and Scheuermann, A. 2010. MOVE: Architecture in Motion-Dynamic Components and Elements. Basel: Birkhauser.

[11] Stevenson, C. 2011. "Morfological Principles: Current Kinetic Architectural Structures.” In Adaptive Architecture, The Building Centre.

[12] Del Grosso, A., and Basso, P. 2013. "Deployable Structures.” Adv Sci Tech 83: 122-31.

[13] Adrover, E. 2015. Deployable Structures. London: Laurence King Publisher.

[14] Escrig Pallares, F., and Pérez Valcárcel, J. 1986. "Introducción a la geometría de las estructuras espaciales desplegables de barras.” Boletin Acad 3: 48-57.

[15] Escrig, F. 1984. "Estructuras espaciales de barras desplegables.” Inf. Constr. 36 (365): 35-46.

[16] Escrig, F. 1984. P-532117. "Sistema Modular para la Construcción de Estructuras Desplegables.”

[17] Escrig, F. 1985. "Expandable Space Structures." Space Struct. Int. J. 1 (2): 79-91.

[18] Escrig, F., and Brebbia, C. (eds.) 2000. Mobile and Rapidly Assembled Structures. Southampton: Computational Mechanics Publications.

[19] Escrig, F., Valcárel, J. P., and Sánchez, J. 1998. "Roofing Geometry of Deployable X-Frames.” Int. J. Space Struct. 13
(1): 1-12, doi: 10.1177/026635119801300101.

[20] Escrig, F. 1993. "Expandable Structures with Incorporated Roofing Elements.” In Space Structures 4. London: Thomas Telford, 804-12.

[21] Soto-Rubio, M., and Jew, C. 2019. "Comparative Structural Evaluation and Analysis of Modular Deployable Structures of Expandable Frames.” In Proceedings of the IASS Annual Symposium 2019.

[22] Valcárcel, J. P., and Escrig, F. 1992. "Expandable Triangular Cylindrical Vaults.” Presented at Actas del Congreso Internacional sobre los Métodos Numéricos en Ingeniería y ciencias Aplicadas, Chile.

[23] Escrig, F., and Valcárcel, J. P. 1988. "Estructuras Espaciales Desplegables Curvas.” Inf. Constr. 39 (393): 53-71.

[24] Escrig, F., and Perez Valcarcel, J. 1993. "Geometry of Expandable Space Structures.” Int. J. Space Struct. 8 (1 \& 2): 71-84.

[25] Escrig, F., and Sanchez, J. 1999. "Estructuras Moviles Para Recintos Circulares.”

[26] Hoberman, C. 1991. US5024031A. "Radial Expansion/Retraction on Truss Structures.”

[27] Escrig Pallares, F., Pérez-Valcárcel, J., and Sánchez-Sanchez, J. 1996. "Las cubiertas desplegables de malla cuadrangular." Boletín académico 20: 36-46.

[28] Roovers, K., and De Temmerman, N. 2015. "Digital Design of Deployable Scissor Grids Based on Circle Packing.” In Proceedings of the International Association for Shell and Spatial Structures.

[29] Valcarcel, J., Escrig, F., Estevez, J., and Martin, E. 1992. "Large Span Expandable Domes." Presented at the International Conference on Large Span Structures, Toronto.

[30] Escrig, F., and Sanchez, J. 2006. "New Designs and Geometries of Deployable Scissor Structures.” Presented at the Adaptables 2006 International Conference on Adaptable Building Structures, Eindhoven.

[31] Escrig, F., Perez Valcarcel, J., and Sanchez, J. 1996. “Deployable Cover on a Swimming Pool in Seville.” J. Int. Assoc. Shell Spat. Struct. 37 (120): 39-70.

[32] Escrig, F., Perez Valcarcel, J., and Sanchez, J. 1995. "Deployable Structures Squared in Plan. Design and Construction.” In Proceedings of the International Association for Shell and Spatial Structures, 483-92.

[33] Escrig, F., Sanchez, J., and Valcárcel, J. P. 1996. “Two Way Deployable Spherical Grids.” Int. J. Space Struct. 11 (1-2): 257-74. 